\title{
Female education and its impact on fertility
}

\section{The relationship is more complex than one may think}

Keywords: female education, fertility, demand for children, fertility control costs, returns to education, family planning

\section{ELEVATOR PITCH}

The negative correlation between women's education and fertility is strongly observed across regions and time; however, its interpretation is unclear. Women's education level could affect fertility through its impact on women's health and their physical capacity to give birth, children's health, the number of children desired, and women's ability to control birth and knowledge of different birth control methods. Each of these mechanisms depends on the individual, institutional, and country circumstances experienced. Their relative importance may change along a country's economic development process.

\section{KEY FINDINGS}

\section{Pros}

$\oplus$ The fertility gap between women with primary vs no education widens as incomes increase, but decreases at higher (secondary vs primary) education levels.

$\oplus$ Educated women are more physically capable of giving birth than uneducated women; but want fewer children and control birth better.

(- Educated women provide better care at home, thus increasing the value of their children's human capital and reducing the need for more children.

- At relatively early stages of a country's development, educated women adopt modern birth control methods more often than uneducated women.
Female schooling and fertility, 2010 (selected countries)

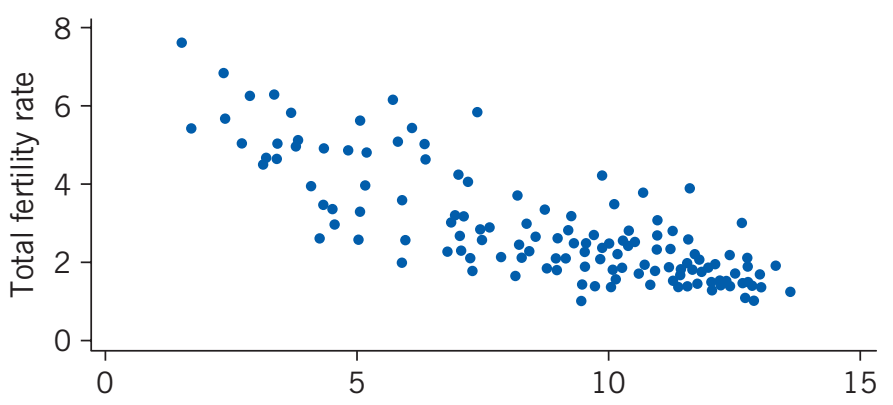

Completed years of schooling for women of reproductive age

Source: Author's own calculations based on Barro and Lee (2010) and World Development Indicators.

\section{Cons}

- The negative correlation between female schooling and fertility is strong but not the same across countries; it varies at different levels of women's education and stages of a country's development.

- Each factor affecting fertility works in certain settings, but the relative importance of each one is unknown.

- Parents' ability to generate wealth may be transferred to their children through investment in children's human capital.

- It is unclear whether education increases women's access to new information or their ability to adopt new birth control technology.

\section{AUTHOR'S MAIN MESSAGE}

Three mechanisms influence the fertility decision of educated women: (1) the relatively higher incomes and thus higher income forgone due to childbearing leads them to want fewer children. The better care these women give increases their children's human capital and reduces the economic need for more children; (2) the positive health impacts of education, on both women and their children, mean women are better able to give birth and children's higher survival rate reduces the desire for more; and (3) the knowledge impact of education means women are better at using contraceptives. For developing population policies, it is thus important to understand these impacts on income, health, and knowledge, and their influence on fertility decisions in the specific country context. 


\section{MOTIVATION}

Educated women generally have fewer children than uneducated women. This negative relationship is strong and varies across both developed and developing countries (measured by GDP per capita) and among women of different education levels. This is not surprising, since countries differ in their various institutional aspects, including education quality. Further, different education levels can generate different kinds of incentives. For example, bettereducated women tend to have better jobs and earn higher incomes, thus the forgone earnings from taking care of children would be higher for these women. Thus, women with primary education tend to have $0-30 \%$ fewer children than uneducated women (ratio of total fertility rate of 1 to 0.7 ). The differential, if any, tends to widen as income increases. Further, women with secondary education tend to have $10-50 \%$ fewer children than those with primary education (ratio of total fertility rate of 0.9 to 0.5 ), with gaps narrowing as income increases (Figure 1). It would be useful for policymakers to understand the mechanisms through which female education affects fertility in the contexts in which these outcomes are observed.

Figure 1 . Women's total fertility rates decrease at increasing levels of income

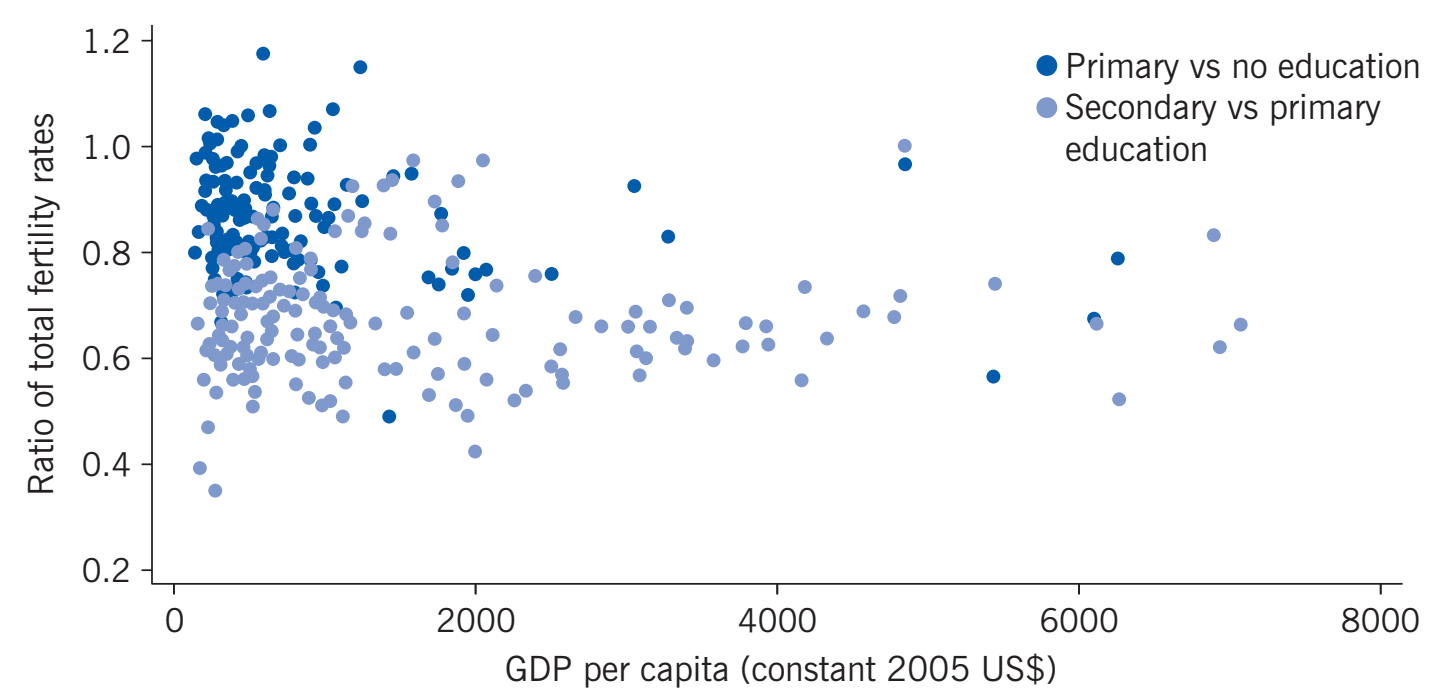

Note: The total fertility rate (TFR) ratio is the TFR of the more-educated women, in each panel, divided by that of the less-educated women. The lower the TFR, the stronger the correlation between women's education and fertility. Data are taken from 221 surveys over 75 countries between 1985 and 2014.

Source: Author's own calculations, based on data from: USAID STATcompiler, 2015. Online at: http://www.statcompiler.com/

\section{DISCUSSION OF PROS AND CONS}

\section{What is the causal effect of education on fertility?}

In principle, women who attend school may have different ideas on family size than those who do not attend school. Hence, economists have questioned whether the observed correlation between women's education and fertility is causal. The illustration on p. 1 shows that countries with a higher share of better-educated women tend to have lower fertility rates. However, even at similar levels of schooling, fertility rates differ across countries, suggesting that other factors might also influence fertility. 
Researchers have observed women's access to education in order to determine whether this has an impact on fertility. A US study compared areas by number of colleges present, and found that female college graduates have $20 \%$ fewer children, on average, than high-school graduates [1]. In contrast, another study examined women born before and immediately after the school entry date, in the US, concluding that education does not have a significant impact on fertility [2]. These different results may be because researchers investigated different populations, in different regions and time periods. The former examined a sample of child births between 1970 and 1999, whereas the latter dealt with a sample between 1989 and 2002. More importantly, the former focused on women who would be expected to change their decision to go to college, depending on the availability of colleges close by, whereas the latter analyzed women whose educational outcomes would potentially be affected by school entry date.

Sudden changes in legislation also offer a chance to verify the causal effect of women's education on fertility. Between 1960 and 1972 the Norwegian government implemented an educational reform that extended compulsory schooling from seven to nine years. This reform was gradually introduced, with each municipality deciding when to adopt it. One study compared female students who were born in the same year but in areas that differed by reform status [3]. It found that the reform increased female schooling by an average of 0.1 years. However, total fertility did not change, possibly because Norwegian women already tended to postpone childbearing until their 20 s or 30 s.

Israel offers another example of the education-fertility nexus. In 1948, Israel's military government placed a restriction on its Arab population traveling within the country. In 1963, it lifted the restriction due to growing public opinion in favor of democracy. Arab children could freely move across localities to attend school if there was no school nearby. Observing the same areas before and after the change revealed that Arab girls' schooling increased by one year and their fertility declined by 0.6 children, on average, after the travel restriction was removed [4].

A school construction program that took place in Indonesia between 1973 and 1978 provides an example for a developing country. One study found that an increase in women's education by one year, compared to their husband's education level, reduced their fertility at age 25 , by 0.1 children, on average [5]. A study on Nigeria investigated a universal primary education program that took place between 1976 and 1981, and found that it also influenced fertility behavior [6]. Accordingly, women with an additional year of schooling had, on average, 0.26 fewer children before age 25 than they would otherwise have had. Both studies compared students from the same area before and after the education programs were introduced. Findings show innate differences in the preference for children between educated and uneducated women. However, they do not explain why better-educated women have fewer children nor do they determine which mechanisms (associated with education) were involved.

\section{Mechanisms for the relationship between female education and fertility}

Women's education may have different effects on fertility through various mechanisms. Fertility can be considered as the maximum number of children a couple could have (supply) minus the number it deliberately avoids having (fertility control). Alternatively, it may be viewed as the sum of the number of desired (demand) and unplanned children. Improvements in women's education affect fertility through the number of children a couple can have, the number of children it wants, and the ability to control birth through the availability of modern 
contraceptives and the knowledge of how to use them. A woman's actual number of children falls somewhere between the number she desires and her natural fertility level. The influencing factors are age and fertility control.

\section{Supply of children}

The supply of children is the number of children a woman is physically capable of bearing. This can be measured by the maximum number of surviving children a couple would have if they did not intentionally attempt to control family size. When better-educated women have more maternal knowledge than less-educated women, e.g., with regard to prenatal care and child nutrition, they can be expected to have higher fertility and infants with better survival prospects.

Recent studies generally support this. For example, the study on the availability of colleges in the US also finds that an additional year of maternal education reduces the incidence of low birth weights by about $10 \%$ and premature births by $6 \%$ [1]. On the other hand, the US study on school entry date suggests that the effect of an increase in maternal education on infant health is only small [2]. The study on the Indonesian school construction program estimates that an additional year of maternal schooling reduces child mortality by about one-third [5]. Another study examined Taiwan, where in 1968 the government extended compulsory education from six to nine years [7]. An increase in maternal education by one year led to a reduction in infant mortality by between $7 \%$ and $9 \%$.

The maximum number of children a couple can have also depends on how long they have been in a relationship. If higher-educated women delay marriage or cohabitation, due to opportunities in the labor market, then education reduces their fertility due to age. Education may also have an effect on fertility through breastfeeding. Although breastfeeding results in temporary infertility due to lactational amenorrhea, its birth-control effect is less than perfect. As better-educated women generally breastfeed their babies for shorter periods, they face the risk of an earlier subsequent pregnancy than less-educated women.

A 1986 study on the Côte d'Ivoire supports the above findings [8]. The study shows that women aged 55 who achieved lower secondary education reduced their fertility by an average of 0.6 children (by the end of their childbearing years), through an increase in their age at cohabitation; shortened breastfeeding increased their fertility by an average of 1.8 children. Hence, the total effect of education was an increase in fertility by an average of 1.2 children (1.8-0.6). For women aged 35, the effect of achieving lower secondary education was a slightly lower decrease in fertility by an average of 0.5 children through an increase in age at cohabitation. (The breastfeeding effect for this group was not detected, possibly due to the offsetting effects of more of these women using contraceptives.) These results are based on a country with a total fertility rate of seven children and GDP per capita of US\$1,258 (in constant 2005 dollars). However, in countries where the average number of children is one or two, education's effect on fertility, through the timing of cohabitation and the duration of breastfeeding, is likely to be smaller.

The possibility that education may limit women's exposure to pregnancy could be more relevant to teenage girls. In school, girls have fewer opportunities to become pregnant than if they are not in school. In this context, an extension of mandatory education may generate an "incarceration effect" for teenage girls. The study on Norway's education reform found that one additional year of schooling reduced the chance of teenage pregnancy by eight percentage 
points [3]. Hence, number of years of education can impact the timing of childbearing. Since entering motherhood at a young age may hamper one's career development, the reduction of teenage pregnancy, alone, is an important policy objective.

\section{Demand for children}

The demand for children can be described as the number of children a couple would like to have if they are free to choose. Most theories predict that better-educated women desire fewer children than less-educated women.

The job of raising children at home is usually more time-intensive than working in the labor market. As better-educated women earn higher incomes, they may feel that raising children is the more expensive option because of the income forgone. In this case, wages are not only a measure of the value of the mother's time, they also contribute to family income. If educated women tend to marry educated men, then the income effect would suggest that these women would be expected to have more children because they can afford to. However, this is a theoretical concept and the actual income effect is often small. On the contrary, empirical findings show that as women's incomes increase, they tend to have fewer children. And since the number of years of schooling is an important determinant of earnings, it follows that female education indirectly reduces fertility through their earnings.

When this mechanism is at work, we would expect that differences in employment rates between women's educational groups would also explain the differences in their fertility rates. Figure 2 shows these differences for women with primary versus no education and women with secondary versus primary education, for developing countries. No correlation is found across these countries for either education group. The range of differences in employment rates is broad for both groups, with most of the results falling between -10 and $+10 \%$.

Figure 2. Differences in fertility and employment statuses between women's education

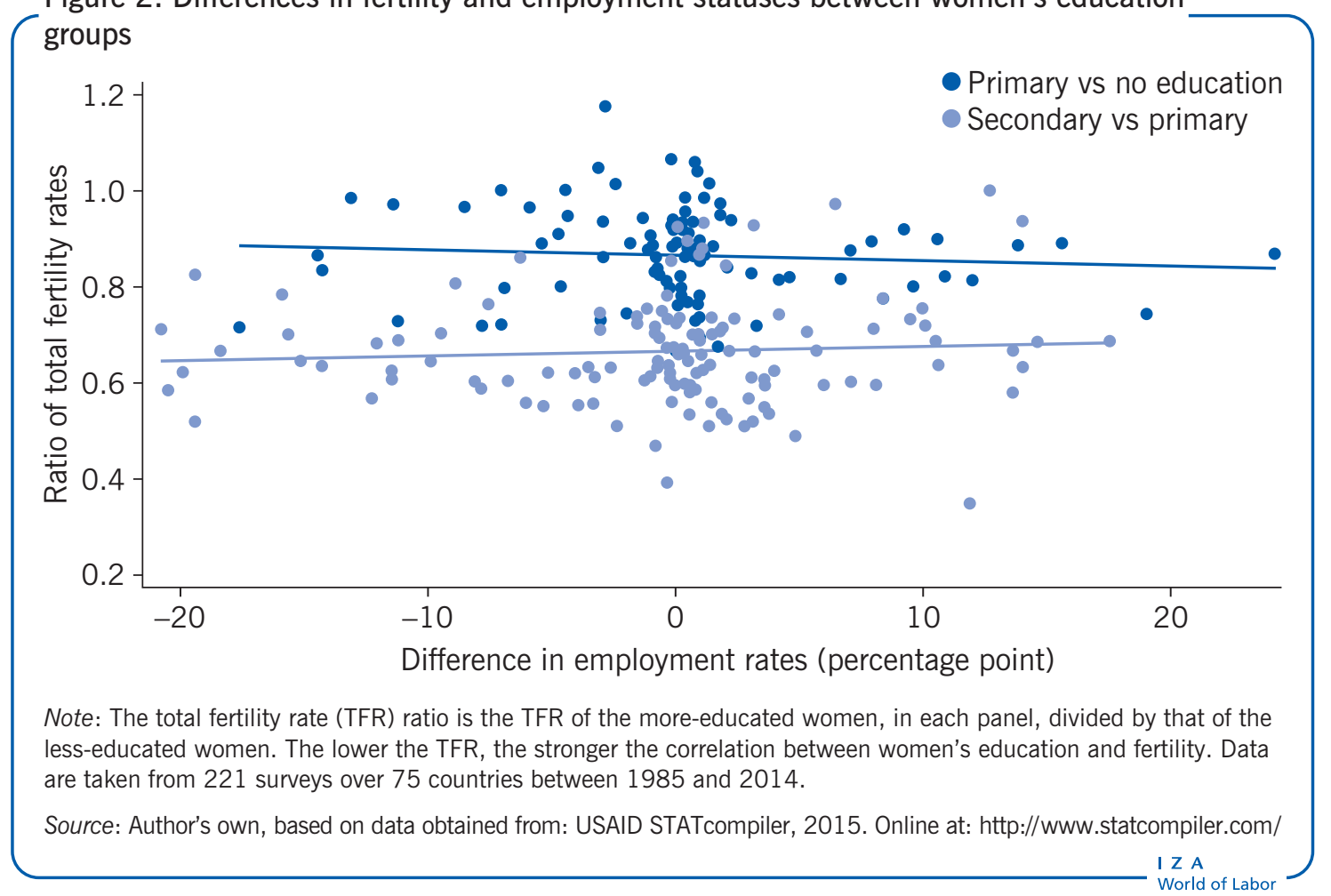


Women's potential opportunities in the labor market do not need to coincide with their actual engagement in employment. Jobs for educated women may not be available in their local labor market, or they may choose to stay at home. This suggests that mechanisms other than women's employment can also have an impact on fertility.

The study on Israel's travel restrictions on the Arab population offers evidence on increased education having no impact on women's employment, as measured by their labor force participation (LFP) rate [4]. The LFP rate is the percentage of the working-age population that is either employed (part- or full-time) or actively seeking work. Findings show that an increase in Arab women's education led to a decline in fertility but did not affect their or their husbands' LFP. The LFP rate for this group of women was low, at around 15\%, and that of their husbands was between $70 \%$ and $90 \%$, before and after the travel reform. One plausible reason for these women's low LFP rate is that education may generate other forms of returns at home. For example, parents with more education may be better able to guide their children's studies, thus preparing them for post-secondary education, better jobs, and higher incomes, or the family may have more financial resources for a parent (usually the mother) to remain at home to raise the children, than those less-educated. In this case, parents with more education would want to have fewer children and invest more in their care. Recent literature supports this.

A study on the impact of women's education in India points out that, during that country's "green revolution," a time of rapid growth in agricultural production during the 1960 s and 1970s, literate women commanded a premium dowry in the marriage market even when the return to female education in the labor market was not observed [9]. Educated men sought to marry educated women because of the higher quality care such wives would provide to any future children. Findings show that children with literate mothers studied for more hours than those whose mothers were illiterate. The authors concluded that the demand for schooled wives, during that period, was mainly due to the potential returns to these women raising better-educated children at home rather than returns to their employment in the labor market.

Other arguments for the impact of women's education on fertility are the role these women's incomes play in improving their families' economic prospects, and the improved social status that comes with higher education. Both mechanisms reduce the need for more children. For a household in a traditional agricultural economy, children are an important source of labor. They are also a source of support during parents' old age. However, as households of women with more education tend to earn higher incomes, they would have less need to rely on children financially. Also, in patriarchal societies, sons are valued more than daughters because they bring their parents a higher social status and are often responsible for taking care of them. In the absence of technology that screens fetuses, the preference for sons often leads to an increase in fertility. However, women with higher education tend to exhibit a weaker preference for sons than less-educated women, due to their financial independence and awareness of gender equality.

\section{Cost of birth control}

As long as there is a gap between the maximum number of achievable births and the desired number of children, a couple has an incentive to control birth. Better-educated women are more likely to be aware of modern contraceptives and to adopt new birth-control methods; their education may also help to improve their bargaining power with their husbands, thereby earning them consent to use contraception in the context of developing countries. 
Evidence shows that the differences in fertility between women's education groups, across developed and developing countries, are indeed strongly correlated with differences in contraceptive use. Figure 3 compares two education groups and shows that an increase in the use of modern contraceptives by 20 percentage points is associated with a decrease in fertility by the same amount. This observation does not confirm the importance of obstacles to birth control, such as a lack of access to a family planning clinic, since women's education both increases the incentive to use contraception and improves knowledge on where to get it and how to use it. However, birth control is far from perfect, even in developed countries. In the US, for example, 2.3\% of women who used a typical contraceptive implant in 1995 had an unintended pregnancy; male condoms failed $8.7 \%$ of the time; and spermicides showed an even higher failure rate at $15.3 \%$.

The case of Indonesia, from the 1970s to the 1990s, offers additional evidence for the role of education in the adoption of contraceptives [10]. While fertility declined among women of all education levels, it fell much faster among better-educated women. It is possible that these women benefited more from a family planning program that was implemented in 1971 and extended to villages, nationally, over the following decade. One issue was that women's fertility behavior may have been related to the location of a family planning clinic. To address this problem, the fertility rates of women in the same village were compared before and after the family planning clinic was set up. It was found that when women had post-primary education and a family planning clinic nearby, the probability of having a second birth was reduced by 12.4 percentage points. With no family planning clinic nearby, the effect was close to zero. These results imply that the effect of education through a family planning program explains threequarters of the total change in the fertility of women with post-primary education, over time. Primary level education helped these women lower their fertility, mainly through increasing their knowledge of contraceptive availability. However, it is unclear whether education enabled these women to have better access to new information, enhanced their ability to learn new technology or improved their bargaining power in the household. The results suggest, though,

Figure 3. Differences in fertility and contraceptive use between education groups

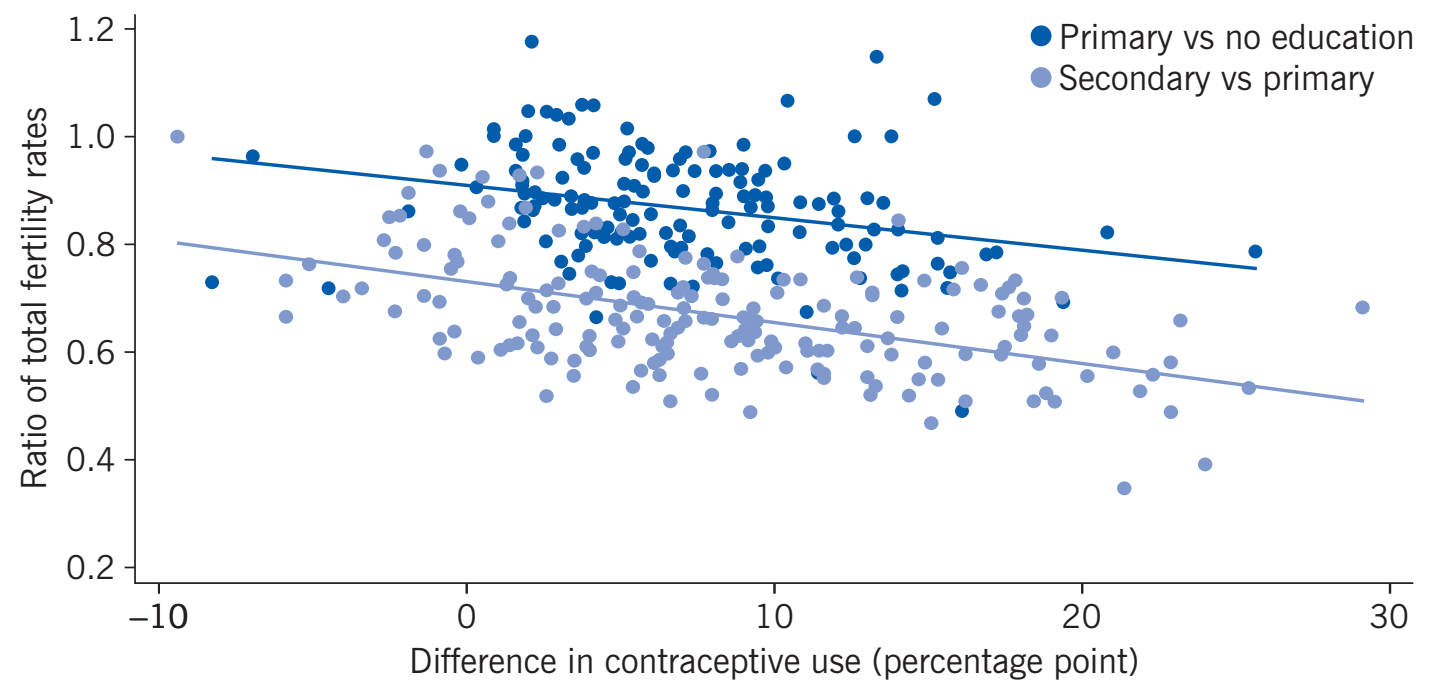

Note: The total fertility rate (TFR) ratio is the TFR of the more-educated women, in each panel, divided by that of the less-educated women. The lower the TFR, the stronger the correlation between women's education and fertility. Data are taken from 221 surveys over 75 countries between 1985 and 2014.

Source: Author's own, based on data obtained from: USAID STATcompiler, 2015. Online at: http://www.statcompiler.com/ 
that the role of a family planning program in fertility decline may be larger than previously thought when its indirect effect through female education is considered.

Contrary to the above finding, one study presents a case wherein access to birth control benefited uneducated women more than educated women [11]. In 1966, the Romanian government banned abortion and family planning. In 1989, after the fall of communism, it legalized both. The study compared fertility behavior immediately before and after the liberalization, and found that fertility decreased by $30 \%$ within six months of the policy change. Further, the fertility differential between women with more than primary education and relatively less-educated women decreased by an average of 0.03 births per year, or more than half the differential. The lifting of the ban on birth control implies that all Romanian women had access to family planning. In other words, modern birth control was not new information, therefore the role of education in the adoption of contraceptives and abortion would be limited. In fact, it is reported that after the 1989 change in legislation uneducated women had, on average, 0.03 abortions per year more than educated women. This may be viewed as uneducated women failing in family planning more often than educated women.

Another argument is that women's higher education empowers them to make decisions on their fertility. In fact, women's empowerment could be the driving force for the effect of education on fertility [12]. An example of this can be seen in Kenya. In 1974, the Kenyan government introduced a family planning program; by the mid-1980s, knowledge of modern contraceptives was widespread. In 1985 the length of primary education was extended by one year. This reform increased women's schooling by 0.74 years and reduced fertility, at age 25 , by an average of 0.3 children. Evidence shows that the education reform increased the use of birth control. This increase was due to the improved autonomy of women on two grounds. First, the reform narrowed the difference in educational attainment between women and their husbands, thereby increasing their bargaining power. Second, the reform also increased the prevalence of HIV/AIDS testing for women, another sign of their increased empowerment.

A family planning program in Bangladesh offers yet another example [13]. In 1977, a family planning and maternal and child health program was implemented in a rural area and became one of the longest running social experiments among developing countries. The program covered 141 villages, half of which were to receive new services in addition to their regular government programs. Every two weeks, fieldworkers visited all women of childbearing age in the treatment area and offered free modern contraceptives and consultations regarding usage. In 1982, services for maternal and child health were added. In 1996, the program was found to have improved various measures of welfare for women aged 30 to 55 and for children. The resulting reduction in fertility did not differ by education level. However, better-educated women in the treatment area experienced higher increases in own income and asset value and they showed lower vaccination take-up rates for their children than women with less education. In this case, for the educated women, the provision of preventive health measures substituted for the vaccinations. Nevertheless, the program's effect on child mortality and physical growth did not differ by the level of education. In sum, the program benefited educated women more than uneducated women in terms of economic activities, but less in access to health services, suggesting that the role of female education in response to new information may be complex and requires further investigation.

\section{LIMITATIONS AND GAPS}

Progress has been made in estimating the causal effect of women's education on fertility. However, study results may not be easily generalized since they are based on subpopulations 
affected by certain policy changes, in certain countries, in certain time periods. For a complete picture, more evidence is needed on the impacts on fertility of different education levels and institutional settings across countries.

So far, less attention has been paid to the mechanisms through which female schooling affects fertility. Theoretical predictions have been in place for years. Yet, the literature has not verified whether female education affects fertility because education generates some forms of return; because it brings home more resources; or because it improves women's bargaining power. Answers to these questions will help predict which subpopulations would benefit more from a particular population policy and program design.

\section{SUMMARY AND POLICY ADVICE}

In both developed and developing countries, better-educated women have fewer children than less-educated women. However, the reasons for this are less clear, since the benefits of education extend beyond the value of women's time. Education can reduce fertility because better-educated women earn more and may raise their children more effectively. Education also improves maternal and child health, thereby increasing a woman's physical capacity to give birth and reducing the (economic) necessity for more children. However, the fact that educated women tend to breastfeed for shorter periods lengthens their exposure to (a new) pregnancy. Nevertheless, understanding modern contraception helps women control birth. Finally, higher education empowers women and includes them in household decisionmaking on family planning. Each mechanism is significant, depending on the individual and institutional context, but there is limited evidence on the relative importance of each one.

The return to women's education as caregivers at home suggests family-friendly policies may allow for a parent to remain at home with their children and invest time in nurturing the next generation. While these policies improve the welfare of both parents and children, they are likely to increase the private transfer of knowledge between generations and, thereby, increase the value of the next generation's human capital. Hence, in the interests of both efficiency and equity, policies should be balanced by strengthening education for the disadvantaged/ less-educated, which could improve their children's long-term prospects in terms of education, employment, and earnings. The returns to education in contraceptive use in both developed and developing countries implies that policies that promote female education complement family planning. However, policymakers should always measure a particular program's costeffectiveness against the alternatives.

\section{Acknowledgments}

The author thanks an anonymous referee and the IZA World of Labor editors for many helpful suggestions on earlier drafts. Previous work of the author contains a larger number of background references for the material presented here and has been used intensively in all major parts of this article [10].

\section{Competing interests}

The IZA World of Labor project is committed to the IZA Guiding Principles of Research Integrity. The author declares to have observed these principles.

(C) Jungho Kim 


\section{REFERENCES}

\section{Further reading}

Jejeebhoy, S. J. Women's Education, Autonomy, and Reproductive Behaviour: Experience from Developing Countries. New York: Oxford University Press, 1995.

Schultz, T. P. "Population policies, fertility, women's human capital, and child quality." In: Schultz, T. P., and J. Strauss (eds). Handbook of Development Economics, Volume 4. Amsterdam: Elsevier, 2007; pp. 3249-3303.

\section{Key references}

[1] Currie, J., and E. Moretti. "Mother's education and the intergenerational transmission of human capital: Evidence from college openings." Quarterly Journal of Economics 118:4 (2003): 1495-1532.

[2] McCrary, J., and H. Royer. "The effect of female education on fertility and infant health: Evidence from school entry policies using exact date of birth." American Economic Review 101:1 (2011): 158-195.

[3] Monstad, K., C. Propper, and K. G. Salvanes. "Education and fertility: Evidence from a natural experiment." The Scandinavian Journal of Economics 110:4 (2008): 827-852.

[4] Lavy, V., and A. Zablotsky. Mother's Schooling and Fertility Under Low Female Labor Force Participation: Evidence from a Natural Experiment. NBER Working Paper No. 16856, 2011.

[5] Breierova, L., and E. Duflo. The Impact of Education on Fertility and Child Mortality: Do Fathers Really Matter Less than Mothers? NBER Working Paper No. 10513, 2004.

[6] Osili, U. O., and B. T. Long. "Does female schooling reduce fertility? Evidence from Nigeria." Journal of Development Economics 87:1 (2008): 57-75.

[7] Chou, S.-Y., J.-T. Liu, M. Grossman, and T. Joyce. "Parental education and child health: Evidence from a natural experiment in Taiwan." American Economic Journal: Applied Economics 2:1 (2010): 33-61.

[8] Appleton, S. "How does female education affect fertility? A structural model for the Côte D'Ivoire." Oxford Bulletin of Economics and Statistics 58:1 (1996): 139-166.

[9] Behrman, J. R., A. D. Foster, M. R. Rosenzweig, and P. Vashishtha. "Women's schooling, home teaching, and economic growth.” Journal of Political Economy 107:4 (1999): 682-714.

[10] Kim, J. "Women's education and fertility: An analysis of the relationship between education and birth spacing in Indonesia." Economic Development and Cultural Change 58:4 (2010): 739-774.

[11] Pop-Eleches, C. "The supply of birth control methods, education, and fertility." Journal of Human Resources 45:4 (2010): 971-997.

[12] Chicoine, L. Education and Fertility: Evidence from a Policy Change in Kenya. IZA Discussion Paper No. 6778, 2012.

[13] Joshi, S., and T. P. Schultz. Family Planning as an Investment in Development: Evaluation of a Program's Consequences in Matlab, Bangladesh. IZA Discussion Paper No. 2639, 2007.

\section{Online extras}

The full reference list for this article is available from:

http://wol.iza.org/articles/female-education-and-its-impact-on-fertility

View the evidence map for this article:

http://wol.iza.org/articles/female-education-and-its-impact-on-fertility/map 